\title{
SELF-POLYMERIZATION OF NANO-FIBRES AND NANO-MEMBRANES INDUCED BY TWO-PHOTON ABSORPTION
}

\author{
M. Malinauskas, G. Bičkauskaitė, M. Rutkauskas, D. Paipulas, V. Purlys, and \\ R. Gadonas \\ Department of Quantum Electronics and Laser Research Centre, Vilnius University, Sauletekio 10, LT-10223 Vilnius, \\ Lithuania \\ E-mail: mangirdas.malinauskas@ff.vu.lt
}

Received 20 December 2009; revised 8 March 2010; accepted 19 March 2010

\begin{abstract}
Laser Two-Photon Polymerization (LTPP) is a technique enabling formation of 3D nanostructures in photosensitive resins with sub-wavelength resolution and unmatched flexibility. However, controllable fabrication of sub-100 nm features by this technique is still a challenge. Self-polymerization, also known as non-local polymerization, is considered to be promising in this ultra-high resolution structure formation. Recent observation of fragile self-polymerized fibres with diameter within tens of nanometres (nano-fibres) encourages the use of self-polymerization to produce nanometre scale structures other than fibres and to define the conditions for controllable fabrication. "X"-shaped polymerized supports are used as rigid structures to produce suspended self-polymerized features of different nature (shape and dimensionality) in-between the walls of "X". By laser writing lines parallel to the substrate and perpendicular to the long symmetry axis of " $X$ " under different conditions, self-formation of periodic nano-fibres (diameter $<100 \mathrm{~nm}$ ) and nano-membranes is induced in acrylate photopolymer AKRE37. Depending on introduced exposure dose, spatial density threshold behaviour of non-structure, nano-fibre, nano-membrane, and laser written lines is deduced. Preliminary model including laser intensity, concentration of radicals, collapse force, and distance between supports as variables having threshold effect on final self-polymerized structure's geometry is proposed to explain non-local self-polymerization.
\end{abstract}

Keywords: femtosecond laser, multi-photon absorption polymerization, acrylate photopolymer, self-assembly, nanotechnology

PACS: 82.50.Pt, 81.16.Dn, 81.05.Zx

\section{Introduction}

Focused femtosecond beam introduces energy in a highly localized volume of a bulk photoresist via multiphoton absorption at the focal point. Pre-polymer containing special photoreactive molecules (photoinitiators) are excited at the beam waist. Generated radicals initiate local irreversible cross-linking reaction resulting in formation of tiny rigid polymerized structures voxels (volumetric pixels) [1]. These photomodified volumes can be produced in a serial manner by exposure to light of the photoresist and joined together in a way to form any desirable 3D structure. After processing by laser beam, unexposed material is washed out during the development process so that only free-standing 3D structures anchored to the substrate remain. Nonlinear character of the two-photon absorption and chemical threshold of required radical concentration $\left(C_{\text {th }}\right)$ for irreversible cross-linking results in high localization of the photomodified volume and the minimum size of a voxel being far below the size of beam waist limited by diffraction [2]. Thus, moving of the beam focal position in 3D enables Direct Laser Writing (DLW) of arbitrary polymer structures with sub-wavelength resolution [3]. This DLW technique often referred to as LTPP has emerged as a tool for the rapid, cheap, and flexible fabrication of 3D nanostructures in photonics, microoptics, nanofluidics, and nanomechanics. Though the lateral size of the smallest features of 3D structure fabricated by LTPP can be as small as $100 \mathrm{~nm}$, further decrease in size is of great importance and feasibility to produce sub-100 nanometre structures still represents an appealing challenge.

Recently, self-polymerization of fragile fibre-like structures with sub-100 nm diameter suspended inbetween rigid supports has been reported when the distance between the supports is below critical value, $D_{\text {th }} \sim 1 \mu \mathrm{m}[4,5]$. Critical distance refers to a maximum spacing between the supports suitable for selfpolymerized features yet to form and sustain rinsing. 
<smiles>C=CC(=O)OCCn1c(=O)n(CCOC(=O)C=C)c(=O)n(CCOC(=O)C=C)c1=O</smiles>

(a)

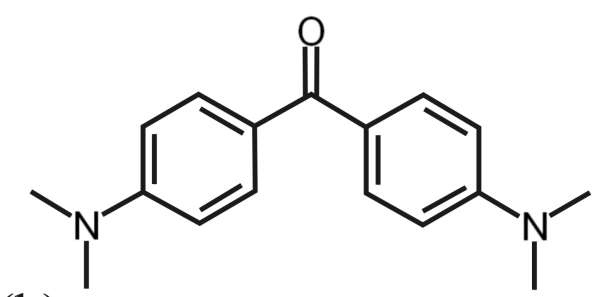

(b)

Fig. 1. Skeletal formula of (a) tris(2-hydroxy ethyl)isocyanurate triacrylate and (b) 4,4'-bis(dimethylamino)benzophenone.

Self-polymerization occurs when laser generated radical concentration becomes close to a threshold value $\left(C \sim C_{\text {th }}\right)$ and is enough to self-assemble into a feature which sustains rinsing in an organic solvent. Long Exposure Technique (LET) has been proposed by Park et al. [4] to induce and control self-polymerization of nano-fibres at the interior region of rigid microstructures. Weakly polymerized regions consisting of ShortChained-Polymers (SCP) were assumed to form around densely polymerized line patterns formed of LongChained-Polymers (LCP) and vary the lateral size of the voxels via LET. When both sides of the line patterns were close enough that the weakly polymerized regions overlapped ( $D<D_{\text {th }}$ ), numerous ultrafine nano-fibres of less than $30 \mathrm{~nm}$ in diameter appeared throughout the overlapped region. Tan et al. [5] have demonstrated that nano-fibres can be produced in controllable manner by increasing the incident laser power and accelerating scanning speed in order to shorten the exposure time. Both groups named the critical distance $D_{\text {th }}$ to be the most important factor for self-formation of nano-fibres, though their proposed exposure conditions are rather opposing to each other. In our work we present results of experimental study on self-polymerization of nanofibres, as well as 2D case of self-polymerized structures - suspended nano-membranes. This phenomenon is investigated in custom made acrylate photopolymer AKRE37.

\section{Materials and methods}

AKRE37 was made by blending commercially available tris(2-hydroxy ethyl)isocyanurate-triacrylate (Sartomer Company, Inc.) monomer with radical photoinitiator 4,4'-bis(dimethylamino)benzophenone (SigmaAldrich Co.) (Fig. 1). Ethyl alcohol was used as a developer. Self-polymerization has been studied by observing the formation of self-induced structures between the rigid support objects fabricated using LTPP system (for details see [6]). It consists of femtosecond Ti:Sapphire laser ( $80 \mathrm{fs}$ pulse duration, $800 \mathrm{~nm}$ central wavelength, $80 \mathrm{MHz}$ repetition rate), translation stages that move the sample along $X, Y$, and $Z$ axes, $100 \times$ 1.4 NA oil immersion objective that focuses laser beam into the sample, and CMOS camera which allows online observation of the fabrication process. "X"-shaped polymerized supports were fabricated, so that they are anchored to the glass substrate in the drop-casted photoresist. The walls of the structure were fabricated using $24 \mathrm{~mW}$ average laser power $P$ and scanning speed $v$ was kept at $200 \mu \mathrm{m} / \mathrm{s}$. The length of the supports was $100 \mu \mathrm{m}$, they were intersecting at the angle of $20^{\circ}$ to have a gradient change of $D$ and the height of the walls was set to $16 \mu \mathrm{m}$. Self-polymerization has been stimulated by unidirectionally laser writing the network of parallel lines oriented perpendicular to the long symmetry axis of the " $X$ " support. Network of lines was written at $15 \mu \mathrm{m}$ height, keeping $v$ fixed at $200 \mu \mathrm{m} / \mathrm{s}$, but changing $P$ and the period between the written lines $(L)$. With the intention to investigate the conditions for self-polymerized structures to form by different exposure approach, $v$ was kept at the level intermediate in the range of that used by Park's and Tan's groups to fabricate nano-fibres $[4,5]$. After rinsing in ethyl alcohol for 20 minutes at $60^{\circ} \mathrm{C}$ the resulting structures were dried out. Sputtered by $40 \mathrm{~nm}$ gold layer, the samples were examined using Scanning Electron Microscope (SEM).

\section{Results and discussion}

To evaluate the laser writing parameters for the network of lines leading to self-polymerization of nanofibres and nano-membranes, at least five samples were fabricated and examined at every set of writing parameters $(P$ and $L)$ in order to test the repeatability. The lines with period of $0.1,0.3,0.5$, and $0.7 \mu \mathrm{m}$ were written between the walls of the support for several different values of average power $P$, which varied in the interval from 9 to $15 \mathrm{~mW}$ (step-size of $1 \mathrm{~mW}$ ). After analysing the features which were formed between the supporting walls, we identified three types of structures. The first type was self-polymerized films (uniform thin membranes suspended at $15 \mu \mathrm{m}$ height and covering part 


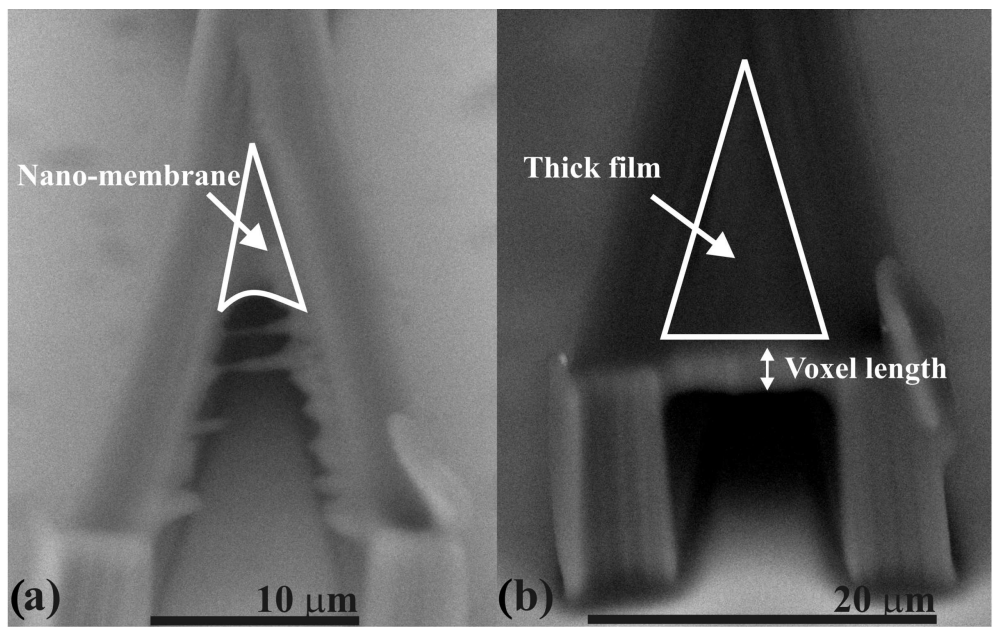

Fig. 2. Two types of formed structures: (a) self-polymerized membrane ( $P$ of $12 \mathrm{~mW}, D$ of $0.6 \mu \mathrm{m})$; (b) thick film $(P$ of $10 \mathrm{~mW}, D$ of $0.3 \mu \mathrm{m})$. Noticeable difference in films' thickness is observed, though due to limited resolution of our SEM the thickness was not measured exactly.

of spacing between the supporting walls, where lines were written). The membrane edges were curved with radius of curvature slightly different at opposite sides of the support. Radius of curvature of the membrane edge was found to depend on the radical diffusion direction along the symmetry axis of the support (perpendicular to the laser written lines). Although the SEM images did not allow accurate measurement of the membrane thickness, it has been estimated to be far below the longitudinal size of the rigid voxels, as was deduced from the SEM images of the samples taken at $45^{\circ}$ angle. Another two types of structures were thick films, forming when fabricated lines overlap at certain $P$ and
$L$ (angular SEM image shows thickness of the film to be equal to the longitudinal size of the voxel, Fig. 2), and separate lines, forming when $L$ is increased. Besides these main types of the structures, cracked films, periodic self-polymerized fibres, and other intermediate structures were also observed in some cases but fabrication conditions resulting in appearance of these structures were not investigated in detail. Probability for each of the three main structural features to form has been roughly estimated by analysing the SEM images of samples which were fabricated using the same $P$ and $L$. If four out of five samples fabricated under the same conditions were of the same type (the same

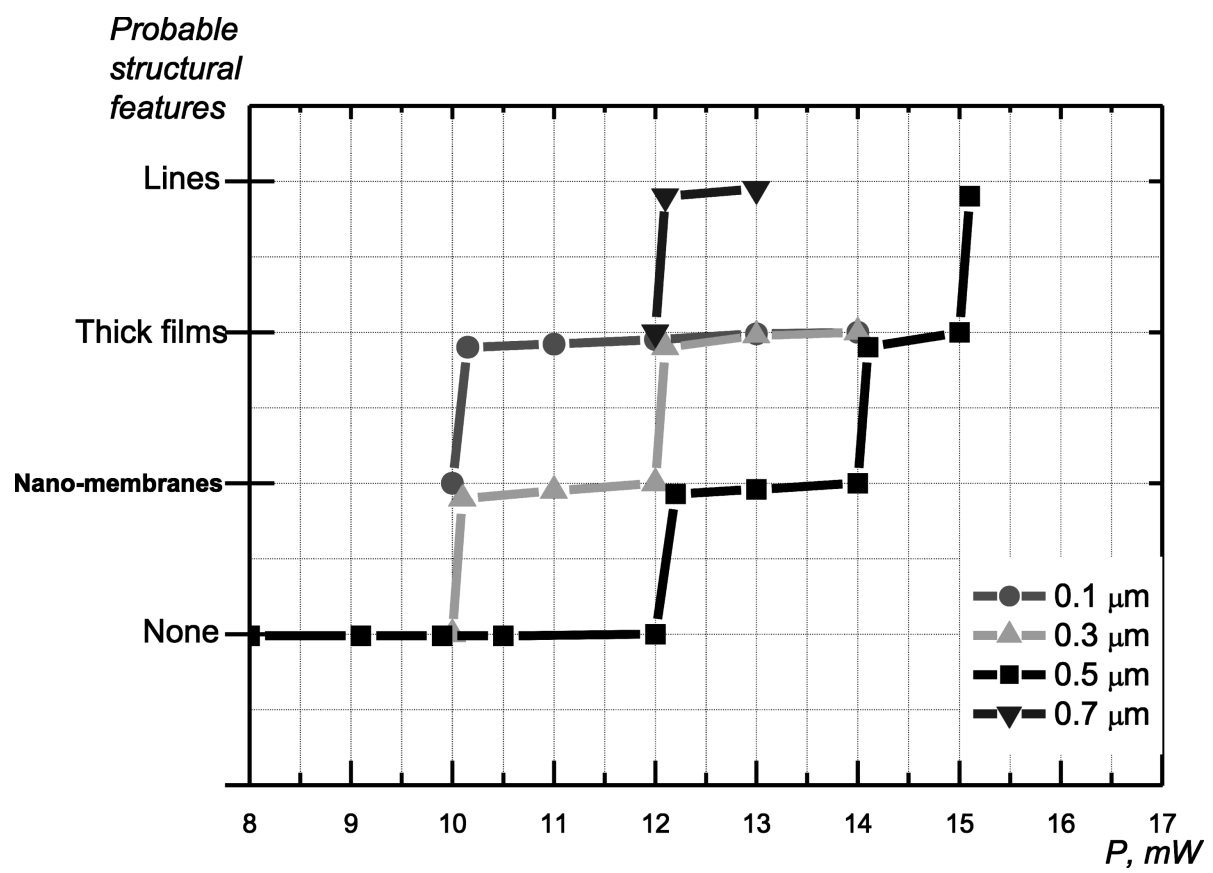

Fig. 3. Threshold behaviour for the self-polymerization of structures by varying average laser power $P$ and lines network period $L$. 


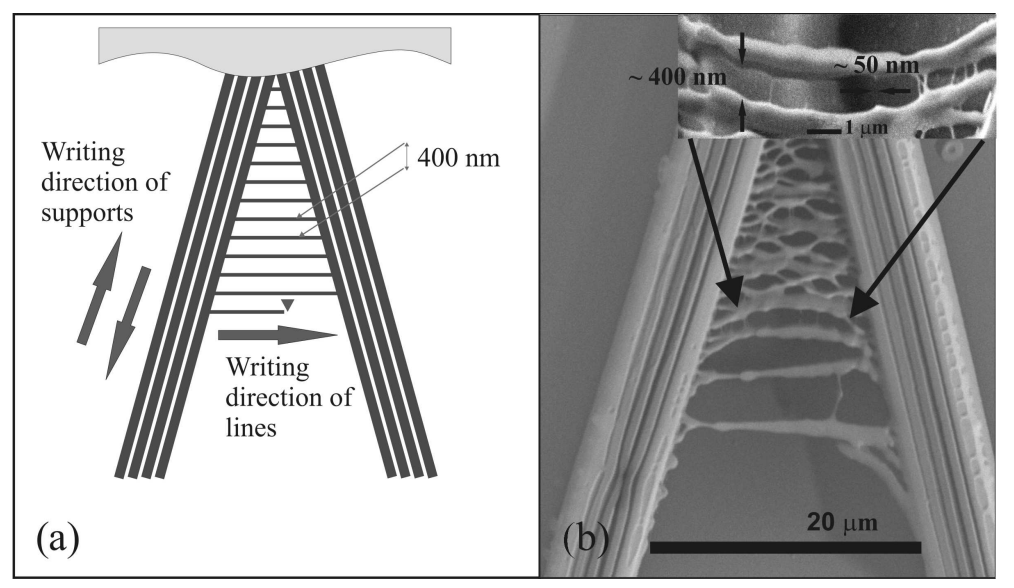

Fig. 4. (a) Image showing the formation of particular "X" structure and lines' network; (b) SEM image of self-polymerized structures in-between the laser polymerized lines ( $P$ of $14 \mathrm{~mW}$, period of $0.7 \mu \mathrm{m}$ ): thin fibres compose within periodic distance in the gap of $0.5 \mu \mathrm{m}$.

kind of the structures formed), the probability for that type structure to form was assumed to be one. Figure 3 reflects the threshold character of self-polymerization in terms of diverse structure formation. It shows that none of the structures appear between rigid supports up to $P$ of $10 \mathrm{~mW}$. Though the threshold power $P_{\text {th }}$ for rigid structures to form in AKRE37 was estimated to be about $12 \mathrm{~mW}$, self-formed membranes were observed both below and above this $P_{\text {th }}$ depending on the density of laser written lines. These self-formed membranes extend over a considerable area so that the distance covered between the supports is much bigger (up to 8 times) compared to the critical distance for nanofibres $(\sim 1 \mu \mathrm{m})[4,5]$. At higher $P$ the formation of thick films instead of thin membranes suspended between the walls was observed. When switching to this type, the structures also showed threshold character for every $L$ of the network. At $P>P_{\text {th }}$, solid lines were formed as expected in LTPP fabrication. $P$ of $10 \mathrm{~mW}$ was found to be enough for self-polymerized membranes to form in-between the walls when the scanned lines were packed densely enough. When writing lines with $L$ of $0.5 \mu \mathrm{m}$ and $P$ of $12 \mathrm{~mW}$, sometimes intermediate structures were formed, including separate lines and small islets of thin film in-between the polymerized and self-polymerized lines. Individual high resolution lines were formed when $L$ was of $0.5 \mu \mathrm{m}$ and $P$ of $15 \mathrm{~mW}$. Periodic nano-fibres of about $50-100 \mathrm{~nm}$ in diameter self-composed in-between the polymerized lines (Fig. 4) were also observed. Those fibres were formed periodically within $\sim 350 \mathrm{~nm}$ in the gap of $400 \mathrm{~nm}$ of previously photopolymerized lines corresponding to the support structures, which tend to interact among each other, resulting in decreased distanced in-between.

Our results show that nano-fibres could self-form when laser writing network of lines at $P \sim P_{\text {th }}$ and at $v$ of intermediate values compared to those in [4, 5]. Under these conditions radical density not sufficient to form robust structural features is generated. To our best knowledge, self-polymerization of nanomembranes has not been reported previously. The films in-between the walls of " $\mathrm{X}$ " form as the SCP may get entangled into the surface layers of the laser written network of lines due to the diffusion dominated processes [7]. During these processes - chain reaction and polymerization termination - the chain elongation proceeds and may result in formation of self-assembled features. Due to capillary forces, self-formed films are concave and curved at the edge. During the rinsing, the solvent evaporates faster from the membrane surface than from beneath it and the capillary forces bend the film downward. The edges of the membrane curve, because evaporation of the solvent makes the polymer shrink. Noticeable difference in radius of curvature of membrane edges dependent on the direction of the line network formation might be explained by the preferential direction of SCP diffusion towards the existing structures (in this case, the " $\mathrm{X}$ " walls) [8]. In one case, the creation of high radical and SCP concentration starts away $\left(D>D_{\text {th }}\right)$ from already polymerized "X" walls and is extended towards the intersection point (" $\mathrm{X}$ " centre) of the walls. This means that chains tend to propagate in the same direction as the concentration of radicals and SCP and do not terminate until LCP meet, which is more likely to happen in the area where irradiation started or near the " $\mathrm{X}$ " walls. If the chain is terminated before one of its ends is attached to the " $\mathrm{X}$ " wall, the whole chain is washed out during the development process. The probability of this to happen reduces as the irradiated area gets closer to the centre of "X". In the other case, radicals and SCP are started to generate already close to the centre of " $\mathrm{X}$ " and tend 




Fig. 5. Images showing the expected profile of lines formation in-between the supports: (a) the model; (b) the actual SEM image of the sample; (c) and (d) magnified images of structure ends reflecting different quantity of formed lines dependent on the direction of network formation.

to connect into chains and attach to the "X" walls first, because the distance needed for those SCP to diffuse towards already polymerized supports is minimal and only increases as the network of exposed lines is extended away from the centre. Therefore, the curvature radius of the membrane edge, formed when radicals are started to generate away from the supports, is smaller than the one of the membrane edge, formed when radicals are started to generate at the centre of "X". For the same reasons, the number of lines polymerized inbetween the supporting walls in the first case discussed is much smaller than in the other (Fig. 5). Obtained results show that the distance between the supporting structures definitely influences the formation of selfpolymerized membranes. That is why $D_{\text {th }}$ plays crucial role in determining self-formation of nano-fibres and nano-membranes. Though our results on studying selfpolymerization of nano-membranes are well consistent with earlier data referring to critically important role of the $D_{\text {th }}$, we suggest that the practical success of controllable fabrication of nano-features is actually greatly influenced by the collapse force threshold $\left(F_{\text {th }}\right)$, emerging during the developer evaporation process, which is the feature of both the material and the structure [9]. To fully describe the critical factors influencing the final self-formed feature, four conditions have to be fulfilled:

1. Average laser power $P \sim P_{\mathrm{th}}$ in order to initiate two-photon absorption;

2. Concentration of radicals $C \sim C_{\text {th }}$ to initiate polymerization chain-reaction;
3. Material rigidity $F<F_{\text {th }}$ in order to prevent the structure from obtaining the geometry provided by the laser trace;

4. Distance between supports $D<D_{\text {th }}$ in order for the SCP to be entangled in higher polymerized regions of supports instead of being washed out.

It is worth to mention that all these parameters are very crucial for self-polymerized features, making them very sensitive to sample processing conditions.

\section{Conclusions}

Our study shows that suspended nano-fibres and nano-membranes can be formed in repetitive manner if appropriate conditions during the laser writing of the line network between solid polymerized supporting structures are provided. Compared to the previously reported works, our experimental results confirm the most important parameter to be the critical distance between the supports. Nevertheless, it contradicts that LET or high scanning laser power and speed are required to induce self-polymerization. Additionally, we found threshold behaviour of non-structure, nano-fibre, nano-membrane, laser written line formation depending on average laser power $P$ and distance between written lines $L$. A simple model is proposed predicting required average laser power, concentration of radicals, material rigidity, and distance between supports for selfpolymerization to be induced. These conditions are defined in relation with the threshold parameters respectively $\left(P \sim P_{\text {th }}, C \sim C_{\text {th }}, F<F_{\text {th }}\right.$, and $\left.D<D_{\text {th }}\right)$ and 
must be satisfied in order to achieve reproducible selfpolymerization of nano-features. Precise control of the femtosecond laser induced self-polymerization could open a way for fabrication of nano-membranes, which could be widely applied in nanomechanics, nanophotonics, and plasmonic metamaterials.

\section{Acknowledgements}

This work is supported by the Lithuanian State Science and Studies Foundation Grant B09/08 (Laser Micro-Processing with High Repetition Femtosecond Pulses - Femtoprocessing). M. Malinauskas would like to thank A. Ovsianikov, A. Kuznetsov, X. Shizhou, and B. Bhuian (Laser Zentrum Hannover, Germany) for the gripping discussions regarding "re-polymerization". Also, acknowledgements are expressed to Sartomer Co. Inc. for providing SR368 material. High quality SEM micrographs were made with the help of P. Gečys (Laboratory of Applied Research, Institute of Physics, Vilnius). Lastly, authors are grateful to A.P. Žindulis (Faculty of Physics, Vilnius University) for gold sputtering the structures.

\section{References}

[1] H.-B. Sun and S. Kawata, Two-photon photopolymerization and 3D lithographic microfabrication, Adv. Polymer Sci. 170, 169-273 (2004).
[2] K. Takada, H.-B. Sun, and S. Kawata, The study on spatial resolution in two-photon induced polymerization, Proc. SPIE 6110, 61100A (2006).

[3] S. Juodkazis, V. Mizeikis, K.K. Seet, M. Miwa, and H. Misawa, Two-photon lithography of nanorods in SU8 photoresist, Nanotechnology 16, 846-849 (2005).

[4] S.-H. Park, T.-W. Lim, D.-Y. Yang, N.-C. Cho, and K.-S. Lee, Fabrication of a bunch of sub-30-nm nanofibers inside microchannels using photopolymerization via a long exposure technique, Appl. Phys. Lett. 89, 173133 (2006).

[5] D. Tan, Y. Li, F. Qi, H. Yang, Q. Gong, X. Dong, and $X$. Duan, Reduction in feature size of two-photon polymerization using SCR500, Appl. Phys. Lett. 90, 071106 (2007).

[6] M. Malinauskas, H. Gilbergs, V. Purlys, A. Žukauskas, M. Rutkauskas, and R. Gadonas, Femtosecond laserinduced two-photon photopolymerization for structuring of micro-optical and photonic devices, Proc. SPIE 7366, 736622 (2009).

[7] H.-B. Sun, K. Takada, and S. Kawata, Elastic force analysis of functional polymer submicron oscillators, Appl. Phys. Lett. 79, 3173-3175 (2001).

[8] J.P. Fouassier and J.F. Rabek, Lasers in Polymer Science and Technology, Vol. 1 (CRC Press, Inc., Boca Raton, $\mathrm{Fl}, 1990)$.

[9] S.-H. Park, K.H. Kim, T. W. Lim, D.-Y. Yang, and K.-S. Lee, Investigation of three-dimensional pattern collapse owing to surface tension using an imperfection finite element model, Microelectron. Eng. 85, 432-439 (2008).

\title{
DVIFOTONE SUGERTIMI INDUKUOTA NANOGIJU IR NANOMEMBRANU SAVIPOLIMERIZACIJA
}

\author{
M. Malinauskas, G. Bičkauskaitė, M. Rutkauskas, D. Paipulas, V. Purlys, R. Gadonas
}

Vilniaus universitetas, Vilnius, Lietuva

\begin{abstract}
Santrauka
Aštriai sufokusuoto pluošto židinyje vyksta dvifotonė sugertis, kuri inicijuoja fotopolimere lokalizuota polimerizacijos reakciją. Po ryškinimo tirpiklyje išlieka tik eksponuota medžiagos dalis, todèl galima gaminti trimates mikrostruktūras. Pastaruoju metu pastebèta gijos formos darinių savipolimerizacija. Tokios nanostruktūros savaime susidaro tarp tvirtu polimerinių atramų, kai atstumas tarp jų yra mažesnis už kritini ( $\left.D_{\mathrm{kr}} \sim 1 \mu \mathrm{m}\right)$. Šiame darbe tiriamas ir aiškinamas nanogijų (skersmuo $<100 \mathrm{~nm}$ ) ir nanomembranų (storis $\sim 100 \mathrm{~nm}$ ) savipolimerizacijos reiškinys akrilatiniame foto-
\end{abstract}

polimere AKRE37. Sufokusuoto femtosekundinio lazerio (80 fs, $800 \mathrm{~nm}, 80 \mathrm{MHz}$ ) pluoštu generuojami radikalai tarp suformuotos „X“ pavidalo atramos sienų rašant lygiagrečias linijas, kai intensyvumas yra artimas slenkstiniam polimerizacijos intensyvumui. Nustatytos sąlygos (vidutinė lazerio galia ir linijų tankis), reikalingos savaime susipolimerizavusiems dariniams (nanogijoms ir nanomembranoms) gauti. Pasiūlytas apibendrintasis modelis, nusakantis savipolimerizacijos sąlygas - lazerio šviesos intensyvumą, radikalų koncentraciją, darinio tvirtumą ir kritini atstumą tarp atramų. 